\title{
A questão da transcendência dos valores e do sentido da vida na análise existencial de Viktor Frankl
}

\author{
Thiago Antonio Avellar Aquino* \\ Josilene Silva da Cruz**
}

\section{Resumo}

Este artigo objetivou clarificar a questão do sentido da vida a partir da ótica da filosofia dos valores presente na Logoteoria de Viktor E. Frankl, atentando sobretudo para o diálogo entre a psicoterapia e a filosofia. Para tanto, realizou-se uma revisitação às suas principais obras e seus influenciadores, a exemplo de Max Scheler e sua teoria dos valores. A pesquisa foi de caráter bibliográfico, cujos resultados demonstraram que a teoria frankliana privilegia a consciência enquanto órgão do sentido como um fenômeno de caráter transcendental, e que os valores, nessa perspectiva, podem ser apreciados numa transcendência horizontal - enquanto realizáveis e acessíveis ao homem, e numa transcendência vertical - como a voz do Supra-ser.

Palavras-chave: Viktor Frankl. Transcendência. Valores. Consciência. Sentido da vida.

\section{The question of the transcendence of values and the meaning of life in Viktor Frankl's existential analysis}

\section{Abstract}

This article aimed to clarify the question of the meaning of life from the perspective of the philosophy of values present in the Logotheory of Viktor E. Frankl, paying attention to the dialogue between psychotherapy and philosophy. For that, a revisit was made to his main works and his influencers, following the example of Max Scheler and his theory of values. The research was bibliographic in character, the results of which demonstrated that the Franklian theory privileges consciousness as an organ of meaning as a phenomenon of transcendental character, and that values, in this perspective, can be appreciated in a horizontal transcendence - while realizable and accessible to man, and in a vertical transcendence - like the voice of the Superbeing.

Keywords: Viktor Frankl. Transcendence. Values. Consciousness. Meaning of life.

* Professor Adjunto da Universidade Federal da Paraíba do Centro de Educação; Doutor em Psicologia (Psicologia Social); Licenciado em Psicologia pela Universidade Federal da Paraíba. E-mail: logosvitae@hotmail.com

** Doutoranda e Mestre em Ciências das Religiões pela Universidade Federal da Paraíba (UFPB); Licenciada em Ciências das Religiões pela mesma instituição. Bolsista CAPES. E-mail: josileneufpb@gmail.com 
Josilene Silva da Cruz.

\section{La cuestión de la trascendencia de los valores y el sentido de la vida en el análisis existencial de Viktor Frankl}

\section{Resumen}

Este artículo tuvo como objetivo aclarar la cuestión del significado de la vida desde la perspectiva de la filosofía de los valores presentes en la Logoterapia de Viktor E. Frankl, prestando especial atención al diálogo entre psicoterapia y filosofía. Con este fin, se realizó una nueva visita a sus principales obras y sus influenciadores, siguiendo el ejemplo de Max Scheler y su teoría de los valores. La investigación fue de carácter bibliográfico, cuyos resultados demostraron que la teoría de Frankl privilegia la conciencia como un órgano de significado como un fenómeno de carácter trascendental, y que los valores, en esta perspectiva, pueden apreciarse en una trascendencia horizontal - mientras que son realizables y accesibles para el hombre, y en una trascendencia vertical - como la voz del Supra-ser.

Palabras clave: Viktor Frankl. Trascendencia. Valores. Conciencia. Significado de la vida.

A Logoterapia e Análise existencial tem sua origem na cidade de Viena, tendo o psiquiatra e neurologista Viktor Frankl como o seu precursor. Constitui-se como uma ciência do logos uma Geisteswissenschaft, que possui tanto aspetos filosóficos e antropológicos quanto práticos em sua constituição como uma escola de psicoterapia. Constata-se que em sua autobiografia Viktor Frankl afirmou sobre o leitmotiv da sua obra: "o esclarecimento da área limite que se estende entre a psicoterapia e a filosofia, com especial atenção à problemática do sentido e dos valores da psicoterapia [...]" (FRANKL, 1990, p. 116-117). Nessa perspectiva, o presente artigo objetivou clarificar a questão do sentido da vida a partir da ótica da filosofia dos valores. Ademais, o autor em questão aventou que o livro de Max Scheler, Der Formalismus in der Ethik und die materiale Wertethik, despertou-o do sono do psicologismo.

Considerando essas duas afirmações do autor, pergunta-se: em que consiste o sono do psicologismo para Viktor Frankl? Qual a visão da transcendentalidade dos valores e dos sentidos da vida para esse autor? Para responder a essas inquietações, consultaram-se tanto os principais escritos do autor, quanto as obras que tangenciam acerca da filosofia dos valores.

\section{O despertar do sono do psicologismo}

A Logoterapia e Análise Existencial descreve a estrutura originária da vivência e realização do sentido da vida; parte da inquietação acerca de quem é o ser e qual o seu sentido. De forma mais específica, questiona: o ser humano dá sentido à vida ou encontra sentido na vida? Frankl se 
posiciona epistemologicamente nesta última vertente, em contraposição ao existencialismo francês que adotou a primeira postura. Nessa direção, torna-se necessário compreender a perspectiva fenomenológica na descrição ontológica dos valores, a qual se afasta tanto do subjetivismo quanto do dogmatismo. Este último não reconhece que o conhecimento seja uma relação entre o sujeito e o objeto, desconsiderando, sobretudo, a esfera do sujeito em sua função de apreender os objetos do conhecimento (HESSEN, 1968).

O subjetivismo, por sua vez, encontra-se na expressão de Protágoras que afirmava que o homem seria a medida de todas as coisas (homo mensura). A verdade está circunscrita ao sujeito cognoscente, o que foi designado de subjetivismo individual (HESSEN, 1968). Essa concepção foi a base do psicologismo das primeiras escolas de psicoterapia. Entretanto, não tardou para que outras vozes também clamassem para uma visão mais ampla do ser, a exemplo de Eucken (1973), quando aventou que "o homem é mais que simples subjetividade e sua vida não se consome completamente no interior de sua esfera particular" (p. 98).

Antes de constituir a sua teoria, o pensador vienense passou por duas correntes: a de Freud e a de Adler. O sonífero que impregnava o pensamento de Frankl estava embebido do subjetivismo decorrente do espírito da época (Zeitgeiste), o que anuviou sua percepção em um dado momento. A outra face do subjetivismo era o naturalismo, que negava o homem e o seu lugar no mundo: "Ora daí a dissolver a sua liberdade e responsabilidade num sistema mecanicista de causas e efeitos, não ia senão um passo" alertou Heimsoeth (1982, p.87).

Assim, considerando a tese do subjetivismo, a teoria moral moderna concebeu que "os valores seriam apenas imagens formadas com sombras, a partir de nossos sentimentos e desejos" (SCHELER, 1994, p. 153). Alerta Scheler que, ao interpretar os valores apenas sob a esfera do sujeito, desconsidera-se sua existência ontológica do objeto e, por conseguinte, destituem-se os valores de seu sentido. Para o autor em baila, os valores possuem um ser, por esse motivo, "[...] eles vêm ao nosso encontro sob a função do sentir, assim como as cores vêm em função do ver” (SCHELER, 1994, p. 154). Essa postura pode ser compreendida como realismo dos valores, que se contrapõe à postura subjetivista.

O psicologismo, por sua vez, seria um derivado do subjetivismo, tendo em conta que "Por psicologismo entende-se aquele processo pseudocientífico que, partindo da origem anímica de um ato, tenta concluir a validade ou invalidade do seu conteúdo espiritual" (FRANKL, 1989, p. 32). 


\section{Thiago Antonio Avellar Aquino}

Josilene Silva da Cruz.

Para compreender a totalidade do homem e do mundo, tornase necessário adentrar a dimensão dos valores espirituais e o seu papel terapêutico, dessa forma, "[...] se no âmbito da psicoterapia deixam de ser considerados como verdadeiros o sentido e os valores, em função dos quais vive o paciente, o próprio paciente já não é tomado a sério como Homem" (FRANKL, 1989, p. 38-39). O psicologismo se manifesta no desmascaramento dos fenômenos genuínos, como se fossem inautênticos. Frankl (1989) dá o exemplo da arte, do amor, da religião e dos grandes espíritos criadores, que foram interpretados como nada mais que uma fuga da vida, medos primitivos das forças cósmicas ou como expressões neuróticas ou psicóticas. Frankl (1978) apontou que os valores foram interpretados apenas como mecanismos de defesa e formações reativas, entretanto, contestou: "No que me diz respeito, nunca será um mecanismo de defesa que dará a vontade de viver, nem me inclinarei para a morte impulsionado por alguma formação reativa" (Frankl, 1978, p. 17).

Para superar o psicologismo, era necessário ancorar o pensamento em uma antropologia filosófica, com o intuito de compreender a totalidade do Homem em sua relação com o mundo. De tal modo,

Sentiu-se a necessidade duma análise filosófica fundamental do Ser hominal encarado na sua posição no universo e ainda sobre o 'sentido' da sua 'existência', tal como este sentido se revela através da experiência da vida não só pessoal como histórica (HEIMSOETH, 1982, p.88).

Pensadores como Heimsoeth (1982) já descreviam o despontar de uma nova filosofia do Homem no Século XX quando afirmavam que “(...) o homem, embora nada mais seja senão um ser da natureza é um ser destinado a destacar-se pouco a pouco, num constante devir, do restante do mundo dos seres vivos" (p. 90). Para o autor supracitado, o especificamente humano emerge como propriedade do espírito humano. (1) Capacidade de consciência e de escolha; (2) capacidade de se distinguir do mundo e de se opor a ele; (3) capacidade de ascetismo, a qual define como:

Atividade voluntária positiva e negativa, que lhe dá a possibilidade de reprimir ou sublimar pelo espírito os seus impulsos vitais, embora esse espírito, por seu lado, seja também forçado a contar com esses mesmos impulsos para toda a realização plena e criadora da vida (Heimsoeth, 1982, p. 92). 
Da mesma maneira, questionou Mounier (2004): “O homem é um ser natural, será somente um ser natural? Será, inteiramente, um joguete da natureza? Inserido na natureza, transcendê-la-á quando dela emerge?” (p. 31). Scheler (2003), por sua vez, sugeriu que a diferença essencial entre o homem e o animal estaria na pessoa espiritual, aquela instância que surge no centro das "esferas finitas do ser". O homem é um ser tanto espiritual quanto sensível, contudo, o psicologismo induziu a pensar que a vida espiritual era mera expressão da vida psíquica, o que se configurou como uma postura reducionista.

No século XX, o psiquiatra do sentido foi o primeiro a desbravar um novo terreno do espírito humano ao apresentar o seu testemunho sobre o homem:

[...] não só como um ser condicionado como um ser incondicionado - do homem como um ser mais que o físico e, em todo caso, como também ainda psíquico, do homem como um ser espiritual, livre e responsável (FRANKL, 1978, p. 178).

Em sua tarefa de reumanização, Frankl verificou que a palavra Ex-sistir significa emergir, ou seja, sair de si mesmo e transcender para os valores na existência, considerando que o ser hominal é aberto para o mundo dos valores (Frankl, 1995). Conforme concebeu o pensador vienense, "o homem desde já tem em vista algo de valor, e por isso, participa no mundo dos valores" (FRANKL, 1989, p. 93). Por conseguinte, o ser humano não é constituído para a autocontemplação ou para a auto-observação, mas para se entregar a algo ou alguém por meio da transcendência de si mesmo, para valores existenciais que estão em potência (FRANKL, 1995). Assim, o despertar do sono do psicologismo requereria bordar a relação entre a vida espiritual e a dimensão ontologia dos valores. O que será abordado a seguir.

\section{Valores e sentidos}

De forma geral, pode-se definir valor como "[...] a qualidade pela qual uma coisa ou ação possui dignidade, é merecedora de consideração, apreço, respeito" (MONDIN, 2005, p. 25). Segundo pensa Mondin (2005), há uma interdependência entre sujeito e valores, pois os valores, embora sejam entendidos como objetos, necessitam de um ser valorante. Dessa forma, "[..] valor é uma propriedade transcendental do ser" (MONDIN, 2005, p. 29). Assim, o autor compreende dois polos do fenômeno dos valores: o subjetivo - a percepção do valor "em mim", e o objetivo - o "ser em si” dos valores. 


\section{Thiago Antonio Avellar Aquino}

Josilene Silva da Cruz.

No intuito de perceber a totalidade do fenômeno, Viktor Frankl não se fixou em apenas um dos polos, posto que, ao excluir o objeto, cairia no subjetivismo e, ao subtrair o sujeito na relação axiológica, redundaria em um objetivismo. O objetivismo coisifica os valores ao desconsiderar o sujeito; enquanto o subjetivismo exifica (verichllicht) ao negá-los. Ademais, de acordo com a ontologia dos valores de Hessen (1967), a questão valorativa não poderia ser reduzida nem ao prazer nem, tão pouco, ao desejável, posto que os valores espirituais não podem ser apreendidos por um estado sensível de sensações. Em consonância com este pensador, asseverou Frankl: "Na realidade, contudo, o homem não é empurrado pelos instintos, mas sim arrastado pelo que tem valor" (FRANKL, 1995, p. 107). O ser humano, nesse ponto de vista, é atraído espontaneamente pelos valores, o que constituiria a mola propulsora da sua dinâmica espiritual.

Destarte, objeto e sujeito em sua unidade constituem a totalidade da vivência valorativa, considerando que em todo fenômeno valorativo há uma referência a um sujeito (HESSEN, 1967). Conforme compreende Modin (2005, p. 30): “[...] o valor emerge no momento em que surge o sujeito, o homem, que realiza um ato positivo de valorização, de estima e que, assim, reconhece a dignidade de uma coisa, de uma pessoa ou de uma ação".

Essa perspectiva é corroborada por meio da teoria do conhecimento que pressupõe o entrelaçamento entre o sujeito e o mundo, assim como a figura do Yin Yang na cultura chinesa (FRANKL, 1978). Nessa referência relacional "sujeito-valor", Hessen (1968, p. 47) afirmou que valor "[...] é a qualidade de uma coisa, que só pode pertencer-lhe em função de um sujeito dotado com uma certa consciência capaz de a registrar". Em outras palavras, se a consciência humana fosse excluída do processo de conhecimento valorativo, jamais o valor seria passível de contemplação. A filosofia dos valores de Scheler pode ser mais bem compreendida como uma perspectiva emocionalista, posto que sua ênfase se encontra na esfera emocional do espírito, em contraposição à perspectiva racionalista kantiana (WOJTYLA, 1993).

A consciência intuitiva (Gewissen) teria a função de captar os valores e os sentidos. Assim sendo, o pensador do sentido compreendeu que "[...] não unicamente o ético e o erótico, não só a consciência moral e o amor têm suas raízes numa profundidade intuitiva e não racional do inconsciente espiritual" (FRANKL, 1992, p. 29). Indubitavelmente, para todos os valores únicos e irrepetíveis há uma referência ao sujeito da experiência valorativa. Frankl denominou de sentido essa experiência singular dos valores, uma 
vez que é pessoal e situacional. Os sentidos são objetos de experiência do indivíduo e se concretizam por meio da ação ou de uma postura interior. Portanto, o papel do logoterapeuta e analista existencial seria o de “[...] ampliar o horizonte de valores do paciente, de modo que ele perceba todo espectro de possibilidades pessoais e concretas do sentido e dos valores" (FRANKL, 1995, p. 155), o que pressupõe a abertura e a transcendência do sujeito para o mundo.

Todavia, compreende-se que há diferenças substanciais entre sentidos e valores no pensamento frankliano. O sentido é um valor único latente em uma situação específica (ad situationem) e demandado para um indivíduo particular (ad personam), já o valor seria um sentido que foi vivenciado e compartilhado por uma comunidade humana, cristalizando-se na historicidade; por esse motivo, poderia ser denominado de "abstratos universais-de-sentido" (FRANKL, 1989, p. 80) ou "possibilidades gerais de sentidos" (FRANKL, 1989, p. 79). Em suas palavras, o autor faz a seguinte distinção: "Enquanto que o sentido está vinculado a uma situação única e singular, existem ainda sentidos universais que se relacionam com a condição humana como tal. São essas possibilidades amplas de sentido que são chamadas valores" (FRANKL, 1992, p. 68).

Como ad situationem, em seu caráter concreto, o sentido é objetividade; e como ad personam, o sentido é subjetividade. Dessa forma, conclui Frankl (1989) que o sentido é "transubjetivo", posto que irradia do mundo para o sujeito. Para fundamentar essa ideia, Frankl recorre à teoria do conhecimento, a qual requer tanto a compreensão da esfera do sujeito quanto da realidade ontológica do objeto. Esta última, para a fenomenologia de Hessen (1968), caracteriza-se por sua transcendência em relação ao primeiro. Conforme expressou Frankl:

“[...] tanto os valores éticos quanto os estéticos requerem, assim como os objetos do conhecimento, atos adequados à respectiva captação; entretanto, sempre tais atos implicam a transcendência dos referidos objetos; quer dizer: estes objetos são transcendentes em relação aos atos que para eles intendem, verificando-se, portando, a sua objetividade" (FRANKL, 1989, p. 74-75).

Outrossim, essa postura leva a pensar que a vida pulsa por meio dos valores, ou seja, “o fim de uma ação é a realização de um valor e não o prazer” (ALLERS, 1958, p. 45). Conforme Allers, quando o ser humano realiza o que é justo, o prazer acontece como um prêmio, o que se pode constatar também no pensamento frankliano: “O prazer se estabelece de um 
Josilene Silva da Cruz.

modo automático na medida em que alguém tenha cumprido um sentido ou realizado um valor" (FRANKL, 2003, p. 54).

Outra importante influência de Max Scheler na obra de Frankl foi a compreensão dos valores dispostos de forma hierárquica, conforme observa:

Para Scheler esse mundo dos valores não só se encontra plenamente ordenado em sua estrutura objetiva, como também sua percepção afetivo-cognoscitiva por parte do homem se distingue por certa ordem apriorística. E trata-se de uma ordem objetiva, visto que o puro sentimento não a cria entre os valores, mas apenas a capta como está disposta. A ordem se expressa em uma estrutura particular de correlações e vínculos entre os valores. Trata-se, sobretudo, de relações hierárquicas; alguns valores são, a priori, superiores a outros. A superioridade a priori de alguns valores sobre outros, percebe-a o homem emocionalmente; não apenas mediante a comparação discursiva recíproca e sim imediata e intuitivamente (WOJTYLA, 1993, p. 22).

Dessa forma, há valores mais nobres do que outros, como, por exemplo, os valores espirituais em comparação aos valores sensíveis. Destarte, são passíveis de uma ordem hierárquica (HESSEN, 1968). Esse pensamento levou Frankl a concluir que as possibilidades de sentidos na existência também possuem uma disposição hierárquica, ou seja, há possibilidades que possuem mais sentido, enquanto outras possuem menos sentido; há um nãodever-ser em contraposição a um dever-ser. A consciência (Gewissen) joga um papel fundamental para clarificar qual valor atrai mais o ser humano em sua ordenação hierárquica, Frankl a define como a "[...] Capacidade intuitiva para seguir o rastro do sentido irrepetível e único que se esconde em cada situação" (FRANKL, 1989, p. 76).

Em vista disso, os valores e sentidos aparentemente podem conflitar, tendo em conta o seu caráter hierárquico. O sentido da situação, em alguns momentos, pode estar em um nível mais elevado em comparação aos valores cristalizados ao longo da história (FRANKL, 1992). Logo, quanto mais amplos forem os valores, menos vinculantes serão, ou seja, quanto mais um valor for absoluto menos vinculado estará a uma situação concreta. Embora o valor absoluto prescreva que não é decente roubar, em algumas situações pode ser a possibilidade que tenha mais sentido, como ocorreu no caso dos prisioneiros nos campos de concentração nazistas. Enquanto o valor absoluto reza que não se deve dar falso testemunho, Frankl precisou falsear os laudos médicos para que alguns pacientes psiquiátricos não fossem submetidos à eutanásia, conforme prescrevia a lei no sistema nazista. Mesmo que não seja 
desejável cometer adultério, quando Frankl foi separado de sua primeira esposa no campo de Auschwitz, suas últimas palavras para ela foi: "permaneça viva a qualquer preço" (FRANKL; LAPIDE, 2014). Por conseguinte, Frankl aventou: "Eu acredito que existem verdades e valores objetivos, mas isso é sempre apenas relativo no sentido de que é relativo a uma determinada pessoa e a uma determinada situação" (FRANKL; LAPIDE, 2014, p. 66).

Nessa direção, Frankl (2016a, p. 168) chega a afirmar que:

Esses valores, no entanto, não podem ser escolhidos e adotados por nós num nível consciente - constituem algo que nós somos. Eles se cristalizaram no curso da evolução da nossa espécie; estão fundamentados no nosso passado biológico e é lá que têm suas raízes [...] se existe uma autocompreensão axiológica pré-reflexiva, podemos supor que ela está ancorada, em última instância, na nossa herança biológica.

Nessa lógica, pode-se compreender que há valores universais que dão sentido à existência, mas, na relação concreta com o mundo, o ser humano os encontra em forma de um sentido único. "O sentido do qual a logoterapia fala nesse contexto não é um sentido universal, mas sim um sentido único" (FRANKL, LAPIDE, 2014, p. 73). Essa mesma ideia se pode encontrar na seguinte pergunta socrática: “[...] visto que aquilo que atua sobre mim é exclusivamente para mim e para ninguém mais, será também o caso de ser eu a percebê-lo e com exclusividade?” (PLATÃO, 2007, p. 71).

Em um diálogo de Frankl com Pinchas Lapide, este último autor discorre sobre a etimologia da palavra sentido no alemão (sinn).

[...] no novo alemão culto, esta palavra vem do alemão culto médio sinan, que significa "ir, viajar, desejar alguma coisa" [...] no velho alemão culto, sinan vem de sintha (sentno), e isso significa "ir em uma direção", no que a direção é presumida como conhecida: em direção a uma meta. Enquanto sinan no alemão culto médio é ir e viajar, de onde vem a bela palavra "experienciar". (FRANKL; LAPIDE, 2014, p. 137)

O sentido, por conseguinte, seria um processo dinâmico, que inclui uma relação entre sujeito e o seu encontro com uma direção ou algo desejável. De forma geral, o ser humano experiencia o sentido por meio de três vias:

Primeiro, pelo que damos à vida (em termos de obras criativas); segundo, pelo que recebemos do mundo (em termos de nossa experiência de valores); e terceiro, pela postura que temos ante um destino que já não podemos 
Josilene Silva da Cruz.

modificar (uma enfermidade incurável, um câncer inoperável). (FRANKL, 2003, p. 30)

De maneira geral, as pessoas encontram sentido ao realizar valores criativos, mas que trabalho criativo dará sentido à vida de um indivíduo seria singular. O ser humano encontra sentido ao vivenciar algo ou alguém, mas o que ele irá vivenciar ou quem irá amar é único. Por fim, a postura que o ser humano toma perante um destino trágico é uma via de realização humana, mas a postura que dará sentido ao sofrimento, no entanto, seria particular.

Se por um lado há valores e sentidos no mundo, por outro, Frankl compreendeu existir uma fé no sentido, o que seria interpretado como uma categoria transcendental kantiana. Logo, "o ser do homem (menschliches Sein) sempre já é ser em função de um sentido, mesmo que não o conheça” (FRANKL, 1992, p. 61).

Nessa via, a teoria do sentido se aproxima do apriorismo, que entende que há fatores a priori, na origem do conhecimento, comparáveis a recipientes, que são preenchidos de conteúdos por meio da experiência (HESSEN, 1968). No caso da Logoterapia, os fatores a priori seriam os valores (forma), por serem mais amplos e não procedentes da experiência, enquanto os conteúdos derivados da vivência se constituiriam como sentidos.

Ademais, influenciado pela perspectiva fenomenológica, o autor concebeu que o ser humano apreende ativamente por meio de sua "autocompreensão ontológica", ou seja, entende que o Homem interpreta a si mesmo como um ente referido a um sentido. Essa autocompreensão seria, então, pré-reflexiva, atentando que o sentido não é apreensível por meio da razão, mas por uma intuição do coração, onde é atraído pela força do sentido.

\section{Dinamicidade dos valores}

Conforme exposto por Hessen (1968), os valores na perspectiva fenomenológica possuem um ser em si mesmo, contudo, a priori, tenham apenas essência. Entretanto, um valor pode encarnar na existência por meio de um ato ou ação no mundo - "os valores, portanto, só podem tornarse existenciais sob a forma de qualidades, características, modos de ser" (HESSEN, 1968, p. 57). Assim, em uma escultura, a pedra seria o suporte para que a estética possa passar de uma possibilidade (essência) para existência (Dasein). Segundo o autor em tela, os objetos, que são portadores, podem 
ser mutáveis, pois a pedra pode ser quebrada, mas o valor em si, o valor da estética, seria imutável, uma vez que entrou na existência.

Seguindo esse pensamento, pode-se concluir que "[...] o mundo real é o infinito de abundância; a vida real é uma vida saturada e inundada, por todos os lados, de valores que a repassam. Para qualquer lado que lancemos a mão, aí encontramos o prodígio e a maravilha" (HARTMANN citado por HESSEN, 1968, p. 64). Hessen (1968), por sua vez, alerta a necessidade de "educar o órgão visual dos valores". Frankl (1992), nessa mesma esteira, aventou que a educação deveria ajudar a aguçar a consciência a captar os valores e os sentidos latentes nas situações.

O autor em foco constatou que a percepção dos valores pode ser comprometida por uma perspectiva niilista, que nega a realidade e a objetividade dos valores na existência; por esse motivo, a Logoterapia prefere expressar que o ser humano deve encontrar sentido - e não dar sentido, pois essa última perspectiva poderia julgar que os valores não existiriam como algo real e objetivo, e seriam nada mais que projeções subjetivas.

Não obstante, o ser humano não poderia se constituir a partir do nada, mas por meio dos valores e dos sentidos que a vida o confronta. Por esse motivo, Frankl (1992) tem um posicionamento crítico em relação à visão de Sartre, posto que, para o último autor, o homem pode se reinventar a si mesmo sem nenhuma referência para os valores. Isso poderia se assemelhar ao truque de faquir, quando ele sobe na corda que lançou para o alto - de forma similar, o homem "[...] projeta seu dever ser no nada, sem que lhe seja oferecido qualquer apoio, e acredita que a partir deste projeto ele possa continuar trabalhando e se aperfeiçoando com sucesso" (FRANKL, 1992, p. 45).

Certa vez, Leonardo da Vinci afirmou: "atrele sua carroça numa estrela”. Dessa forma, Frankl considera que o imperativo de Píndaro "Torna-te o que tu és" não poderia promover um crescimento existencial, considerando que "[...] o homem não precisa estender a mão até as estrelas, para baixá-las a terra, porque a terra é uma estrela!” (FRANKL, p. 2003, p. 25-26). Igualmente, se os valores fossem nada mais que meras autoexpressões, não teria sentido confrontar o ser humano com ideais e sentidos. Assim, pode-se pensar que seria mais adequado afirmar: Torna-te quem tu deves ser.

É necessário compreender que “todo dever (Sollen), apesar de todo ato de querer (Wollen), de alguma forma, está pressuposto. O dever precede ontologicamente o querer" (FRANKL, 1992, p. 45). Assim, a vontade de sentido é despertada na medida em que o ser humano vislumbra valores e sentidos no mundo, dignos de realização em seu campo perceptivo. 


\section{Thiago Antonio Avellar Aquino}

Josilene Silva da Cruz.

Na ótica da Logoterapia e Análise Existencial, “[...] um dos atributos essenciais do ser humano consiste em achar-se num campo de tensão, entre dois polos do ser e dever-ser, em visar o sentido e os valores, abrindo-se para suas exigências" (FRANKL, 1989, p. 89). A esta tensão o autor denomina de dinâmica existencial, seria essencial para a saúde mental e o bem estar, pois, em sua ausência, o ser humano pode adoecer. Frankl compara esta atração espontânea do Homem para o sentido tanto com as limalhas de ferro em um campo magnético, quanto com a gravidade: "Assim como o homem necessita da força atrativa da gravidade (pelo menos em sua vida normal), necessita também da força atrativa que emana do sentido de sua existência" (FRANKL, 2003, p. 37).

Por conseguinte, a compreensão do analista existencial é a de que existem valores no mundo que esperam por realização. Para tanto, o ser humano necessita transcender, ou seja, deve ir além de si mesmo em direção ao sentido para a sua efetivação. A princípio, os valores e sentidos se encontram como possibilidades (poder ser) e entram na realidade por meio da ação, o que torna o ser humano portador dos valores existenciais.

$\mathrm{Na}$ filosofia dos valores, encontramos a seguinte afirmação: "O valor irreal torna-se real, isto é, assume existência, encarna. Um ser, uma essência (Sosein), penetra-se de existentia (Dasein)" (HESSEN, 1968, p. 57). Por conseguinte, por meio dos valores o ser humano é livre para se tornar outro, ou seja, mudar a sua própria essência. "Esse tornar-se outro é sempre orientado para um mundo objetivo de sentido e de valores, [...] essa orientação para o sentido de toda auto-estruturação faz que a verdadeira personalidade não possa ser concebida senão marcada pelos sentidos e pelos valores" (FRANKL, 1978, p. 162).

\section{A transcendência da consciência}

No desenvolvimento de sua teoria, Frankl atenta para as especificidades relacionadas ao sentido da existência. Nessa esfera, ele toca num ponto crucial: a consciência. Ele a define como "um órgão do sentido e não como um órgão sensorial. Isto significa, como aquela instância, que é integrada à constituição do homem como aquele órgão que o deixa descobrir o sentido singular e único da situação presente" (FRANKL; LAPIDE, 2014, p. 65). Nessa perspectiva, compreende-se a consciência como constitutiva do ser, e fenomenologicamente, responsável por clarificar os sentidos da existência. 
Corroborando essa afirmação, Xausa (2019, p. 103) destaca que "O fenômeno da consciência é, para Frankl, um fenômeno primário. Como o ser humano é uma unidade corpóreo-psico-espiritual (noética), tanto o inconsciente como a consciência radicam no espiritual", lembrando que essa referência ao espiritual remete, em perspectiva frankliana, ao que é especificamente humano e não está vinculada a nenhum preceito de religiosidade ou de crença. O noético, ou espiritual, na concepção de Frankl, está para além da perspectiva religiosa - é a dimensão constitutiva única e mais elevada da visão tripartite de homem como um ser bio-psico-espiritual. Nela se torna possível a busca pelo sentido, além de estar diretamente relacionada com a consciência, que consiste na "capacidade humana de encontrar o sentido escondido por trás de cada situação singular” (FRANKL, 2011, p. 108).

Desta forma, constata-se a relevância que possui esse fenômeno para o ser humano, pois, na visão frankliana, ela consiste algo transcendente por natureza. Segundo o pensador vienense, a "consciência como um fato psicológico imanente já nos remete, por si mesma, à transcendência; somente pode ser compreendida a partir da transcendência, somente como ela própria, de alguma forma, constituindo um fenômeno transcendente" (FRANKL, 2016b, p. 50). Nessa direção, Xausa (2019) destaca a transcendentalidade da consciência como uma instância extra-humana,

Frankl trata a consciência sob o ângulo da transcendentalidade. Lembra a etimologia de pessoa que se liga no grego e, mais tarde, no latim, aos conceitos de "soar antes" ou "soar além", retumbar. Aplicado à voz da consciência, isso significa para Frankl que a pessoa humana, persona, remonta a uma instância extra-humana. Passa do plano psicológico para o plano ontológico. (XAUSA, 2019, p. 107)

Relativo a esse plano ontológico, Frankl assevera que "dentro da ontologia do ser humano, não nos será possível compreendê-la em todos os seus aspectos, especialmente a sua consciência, se não recorrermos a uma origem transcendente. A consciência só será inteligível a partir de uma região extra-humana" (FRANKL, 2016b, p. 50), de modo que só é compreensível essa instância numa perspectiva transcendental, como um fenômeno que escapa à apreensão meramente cognitiva.

Ademais, para Frankl, a consciência também é a instância que distingue ou delimita a relação do homem religioso em relação ao não-religioso, pois, enquanto o homem descrente fica em sua asserção de verdade no nível da 


\section{Thiago Antonio Avellar Aquino}

Josilene Silva da Cruz.

consciência, o homem religioso passaria para um outro nível: o divino - e, por esse, motivo não haveria possibilidade dessas duas visões entrarem em confronto, porque encontram-se em níveis distintos. Nesse sentido, ele próprio destaca a concepção de verdade do descrente ou ateu: "obedece somente à sua consciência e que considera esta consciência como um pontofinal - em oposição ao homem religioso, que por detrás da consciência ainda vê uma instância divina -, jamais poderá entrar em conflito com a verdade do homem religioso" (FRANKL; LAPIDE, 2014, p. 58).

De acordo com a exposição, o homem não-religioso direciona seus questionamentos e a concepção de verdade até a sua consciência e, para ele, é o bastante, pois compreende-se como ponto final dessa busca. Já o homem religioso adentra uma instância que se encontra em outro nível, uma dimensão mais profunda e que, para a visão frankliana, denomina-se como o Supra-ser ou Suprassentido. Nessa perspectiva, destaca-se o posicionamento do mentor da Logoterapia acerca desse "sentido último", ele afirma que

Esse sentido último necessariamente excede e ultrapassa a capacidade intelectual finita do ser humano; na logoterapia falamos neste contexto de um suprassentido. O que se requer da pessoa não é aquilo que alguns filósofos existenciais ensinam, ou seja, suportar a incapacidade de compreender, em termos racionais, o fato de que a vida tem um sentido incondicional. O logos é mais profundo do que a lógica. (FRANKL, 2016a, p. 142)

Deste modo, evidencia-se que Frankl não aponta para o Homem irreligioso como alguém que não possa encontrar seus sentidos, ele apenas indica que não é possível apreender esse suprassentido por vias racionais apenas. É importante frisar que Frankl não se posiciona acerca destas visões em termos valorativos, colocando-as em ordem de superioridade, ele apenas as apresenta como constatações. O próprio Frankl (2016b, p. 82) afirma que "a logoterapia não faz julgamento sobre sentido ou falta de sentido, valor ou desvalor", com isso, ele evidencia sua posição de distanciamento perante juízo de valor, seja com relação ao sentido seja com relação aos valores. Por esse ângulo, ele diz

Com outras palavras, o homem não religioso é alguém que aceita sua consciência em sua fatuidade, é aquele que deste fato como um simples imanente quase faz uma parada - faz antecipadamente uma parada. A gente poderia dizer, porque ele considera a consciência como a última instância, diante da qual ele deve se responsabilizar. A consciência não é, porém, a 
última antes do ser responsável; não é nenhuma ulterioridade, mas antes uma anterioridade. A consciência me diz pelo que eu sou responsável, e não diante de quê. (FRANKL; LAPIDE, 2014, p. 114)

Esse é outro elemento significativo na visão de Frankl: a responsabilidade. Liberdade e responsabilidade podem ser vistos como norteadores da busca pelo sentido. Sem essas instâncias o ser humano estaria fadado ao fracasso nessa busca, tendo em vista que elas estão diretamente ligadas à consciência, conforme assevera o pensador vienense:

Toda liberdade tem um "de quê" e um "para quê". O "de quê", do qual o ser humano pode se libertar, está em seu ser impulsionado; seu eu, então, tem liberdade diante de seu id. O "para quê" da liberdade humana é sua responsabilidade. A liberdade da vontade do ser humano é, portanto, a liberdade "de" ser impulsionado "para" ser responsável, para ter consciência. (FRANKL, 2016b, p. 48)

Ele reitera uma de suas sucessoras e amiga, Izar Xausa, apontando para o fato de que "o fenômeno da consciência não se reduz simplesmente à facticidade psicológica, mas em sua transcendentalidade essencial. A voz da consciência estabelece um diálogo que não se reduz a um monólogo. Para Frankl, a consciência é a voz da transcendência" (XAUSA, 2019, p. 107). Assim, "em outras palavras, só posso ser servo da minha consciência, se, na minha autocompreensão, entender a consciência como um fenômeno que transcende minha mera condição humana e, consequentemente, compreender a mim mesmo, a minha existência, a partir da transcendência” (FRANKL, 2016b, p. 49). Além disso, Frankl advoga que:

"Sê senhor da tua vontade..." Bem, sou senhor da minha vontade pelo fato de ser pessoa, contanto que entenda corretamente esse meu ser-pessoa, que é ser livre e plenamente responsável. Se, além disso, devo ser servo da minha consciência”, e para que possa sê-lo, essa consciência deve então ser algo superior à pessoa a qual apenas ouve "a voz da consciência", deve ser algo extra-humano. (FRANKL, 2016b, p. 48-49)

Por fim, compreende-se que, para esse autor, a dinâmica existente relativa à consciência é possível em função da sua transcendentalidade, e sua relevância nessa perspectiva é indiscutível, porque 


\section{Thiago Antonio Avellar Aquino}

Josilene Silva da Cruz.

[...] a consciência não poderia "ter voz", porque ela própria "é” a voz, a voz da transcendência. Essa voz somente é ouvida pelo ser humano, ela não provém dele; ao contrário, somente o caráter transcendente da consciência faz com que possamos compreender o ser humano, e especialmente sua personalidade, num sentido mais profundo. Sob esse ângulo, o termo "pessoa" adquiriria um novo significado, pois agora podemos dizer: através da consciência da pessoa humana persona* uma instância extra-humana. (FRANKL, 2016b, p. 49)

\section{Considerações finais}

As perguntas levantadas no início deste capítulo foram: em que consiste o sono do psicologismo para Viktor Frankl? Qual a visão da transcendentalidade dos valores e dos sentidos da vida para esse autor? Constatou-se que o sono do psicologismo consiste em reduzir os valores e o sentido a nada mais que processos psíquicos, redundando-os em uma postura subjetivista e imanentista. Dessa forma, é na consciência (Gewissen) que ocorreria o fenômeno da transcendência do Homem para mundo dos valores, seja para um tu, uma causa ou para um supra-Ser. Conclui-se que a vontade de sentido é imanente à condição humana, mas que o sentido consiste no encontro autêntico com os valores transcendentes na existência.

\section{Referências}

ALLERS, R. Psicologia do caráter. Tradução N. L. Rodrigues. 4ed. Rio de Janeiro, Livraria Agir, 1958.

EUCKEN, R. O sentido e o valor da vida. Rio de Janeiro: Editora Opera Mundi, 1973.

FRANKL, V. E. Fundamentos Antropológicos da Psicoterapia. Rio de Janeiro: Zahar Editores, 1978.

FRANKL, V. E. Psicoterapia e sentido da vida. São Paulo: Quadrantes, 1989.

FRANKL, V. E. A questão do sentido em Psicoterapia. São Paulo: Papirus Editora, 1990.

FRANKL, V. E. A presença ignorada de Deus. Petrópolis: Vozes; São Leopoldo: Sinodal, 1992.

FRANKL, V. E. Logoterapia e análise existencial. Campinas: Editorial Psy II, 1995.

FRANKL, V. E. Psicoterapia y existencialismo: Escritos selectos sobre logoterapia, 2003.

FRANKL, V. E. A vontade de sentido: fundamentos e aplicações da logoterapia. [Trad. Ivo Studart Pereira]. São Paulo: Paulus, 2011.

FRANKL, V. E.; LAPIDE, P.. A busca de Deus e questionamentos sobre o sentido: um diálogo. $2^{\mathrm{a}}$ ed. [Trad. Márcia Neuman]. Petrópolis, RJ: Vozes, 2014.

FRANKL, V. E. Em busca de sentido: um psicólogo no campo de concentração. [Trad. W. O. Schlupp e Carlos C. Aveline]. 40ª ed. São Leopoldo: Sinodal; Petrópolis: Vozes, 2016a. 
FRANKL, V. E. A presença ignorada de Deus. [Trad. Walter O. Schlupp e Helga H. Reinhold]. 17ª ed. São Leopoldo, RS: Sinodal; Petrópolis: Vozes, $2016 \mathrm{~b}$.

HEIMSOETH, H. A filosofia do século XX. Coimbra: Editora Armênio Amado, 1982.

HESSEN, J. Teoria do conhecimento. Coimbra: Editora Armênio Amado, 1968.

MONDIN, B. Os valores fundamentais. Bauru, SP: EDUSC, 2005.

MOUNIER, E. O personalismo. São Paulo: Centauro Editora, 2004.

PLATÃO. Diálogos: Teeteto (ou do conhecimento), Sofista (ou do ser), Protágoras (ou sofistas). Bauru, SP: EDIPRO, 2007.

SCHELER, M. Da reviravolta dos valores. Petrópolis, RJ: Vozes, 1994.

SCHELER, M. A posição do homem no cosmos. Rio de Janeiro: Forense Universitária, 2003.

WOJTYLA, K. Max Scheler e a ética cristã. Curitiba: Champagnat, 1993.

XAUSA, I. O sentido dos sonhos na psicoterapia em Viktor Frank1. Belo Horizonte: Editora Artesã, 2019.

Submetido em: 30-6-2020

Aceito em: 14-8-2020 